\title{
The Measurement of Temperature in the Stratosphere and Mesosphere
}

\author{
HAROLd N. BALLARD \\ Almospheric Sciences Laboratory, While Sands Missile Range, N. Mex.
}

(Manuscript received 3 June 1966, in revised form 12 September 1966)

\begin{abstract}
Careful consideration of the heat transfer equations for a rocket-borne stratospheric temperature sensor in the form of a spherical bead thermistor coupled with an experimental analysis of the physical, thermodynamic and electrical characteristics of the rocketsonde, indicated that the corrections to the observed thermistor temperatures could be substantially reduced through development of a new rocketsonde. Redesign of the rocketsonde temperature sensor reduced the theoretical temperature correction at $65 \mathrm{~km}$ from a value of $36 \mathrm{C}$ for the Delta-I temperature sensing instrument to approximately $6 \mathrm{C}$ for the new design. Temperature data obtained with the new stratospheric temperature sonde STS-1 showed that, after instrument expulsion at $74 \mathrm{~km}$ and at rocket nose-cone temperature near $100 \mathrm{C}$, the thermistor temperatures at and below $60 \mathrm{~km}$ were, without correction, in close agreement with those predicted by the U. S. 1962 Standard Atmosphere.
\end{abstract}

\section{Introduction}

By the end of the International Quiet Sun Year (IQSY) techniques for the determination of temperature in the stratosphere had been implemented in rocket flights at Meteorological Rocket Network stations through the use of various rocketsonde configurations in which the spherical bead thermistor served as the temperature sensing element. ${ }^{1} \mathrm{Fig} .1$ shows the basic elements of such a system.

1 Ballard, H. N., 1966: The measurement of temperature in the stratosphere and mesosphere. Preprint No. 66-385, Sixth Conf. Applied Meteorology (Aerospace Meteorology), Amer. Meteor. Soc., Los Angeles, Calif.

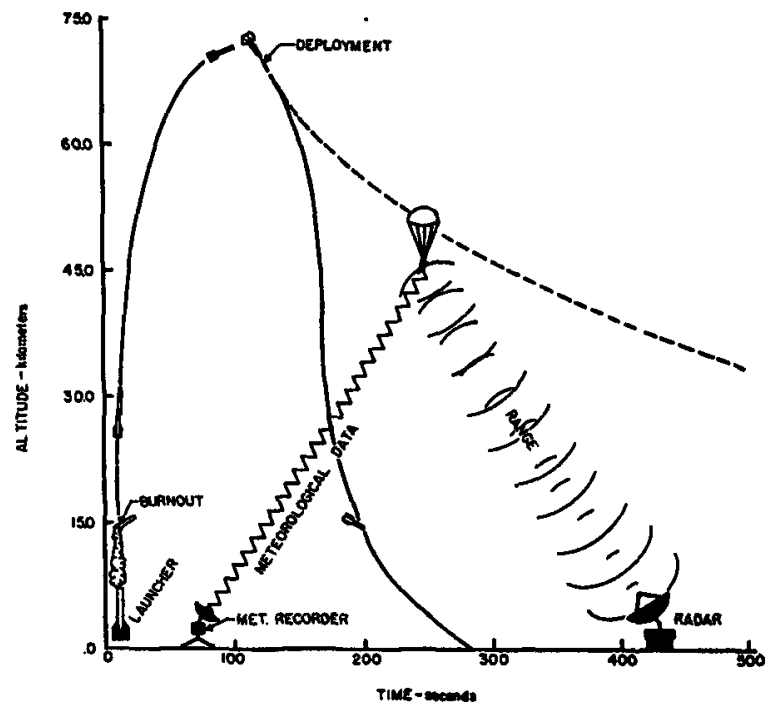

Fic. 1. Temperature and wind sensing system.
Fig. 2 is a typical atmospheric temperature-time record as obtained with the Delta-I type mounting shown in Fig. 3 and recorded on the TMQ-5 meteorological recorder. Fig. 4 shows the corresponding temperature-altitude profiles obtained from the temperature record of Fig. 2 and as corrected according to the Wagner (1964) correction which is presented in Table 1. The correction magnitudes are dependent upon the expulsion altitude and fall velocity of the thermistor. The instrument position was determined by the AN/FPS-16 radar system.

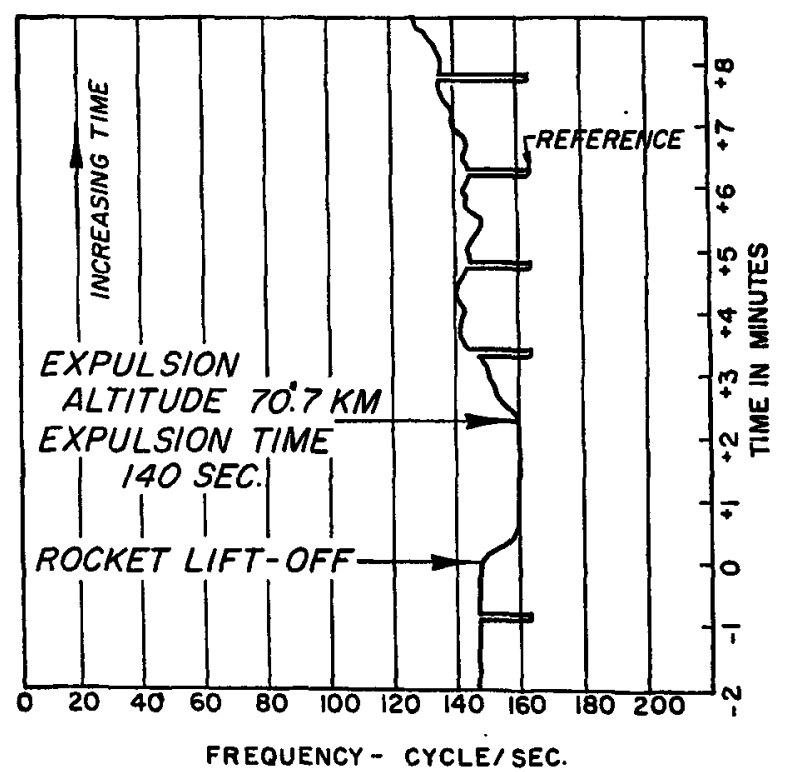

FIG. 2. Temperature-time record, Delta-I instrument. 


\section{Principal modes of heat transfer}

Represented in Fig. 5 are the principal modes of heat transfer between the thermistor and its surroundings. These modes are long wave radiation $R_{b e}$ from the environment below, solar radiation $R_{\varepsilon}$, radio frequency radiation $R_{r f}$ from the rocketsonde transmitter, long wave radiation $R_{a i}$ from the instrument above, long wave radiation $R_{a e}$ from the environment above, long wave radiation $R_{e}$ from the thermistor to its surrounding environment, heat conduction $H_{c d}$ between the thermistor and the thermistor mount, and convective heat transfer $H_{c v}$ between the thermistor and the surrounding air. In the analysis, the convective heat transfer term includes the effects of aerodynamic and ohmic heating of the thermistor bead.

The heat transfer expressions as written in Fig. 5 are similar to those used by Wagner (1964) in a theoretical study concerning the thermal equilibrium of the bead thermistor with a nonsteady-state heat transfer environment.

The numerical values (expressed in microwatts, Fig. 5) for each transfer term are applicable to the Delta-I rocketsonde (Clark and McCoy, 1965) at an altitude of $65 \mathrm{~km}$. The heat transfer rates are indicative of the relative contribution of each heat transfer process. A study of the various terms indicates that there is:

1) A net loss of energy per unit time of $2 \mu \mathrm{W}$ due to long wave radiation.

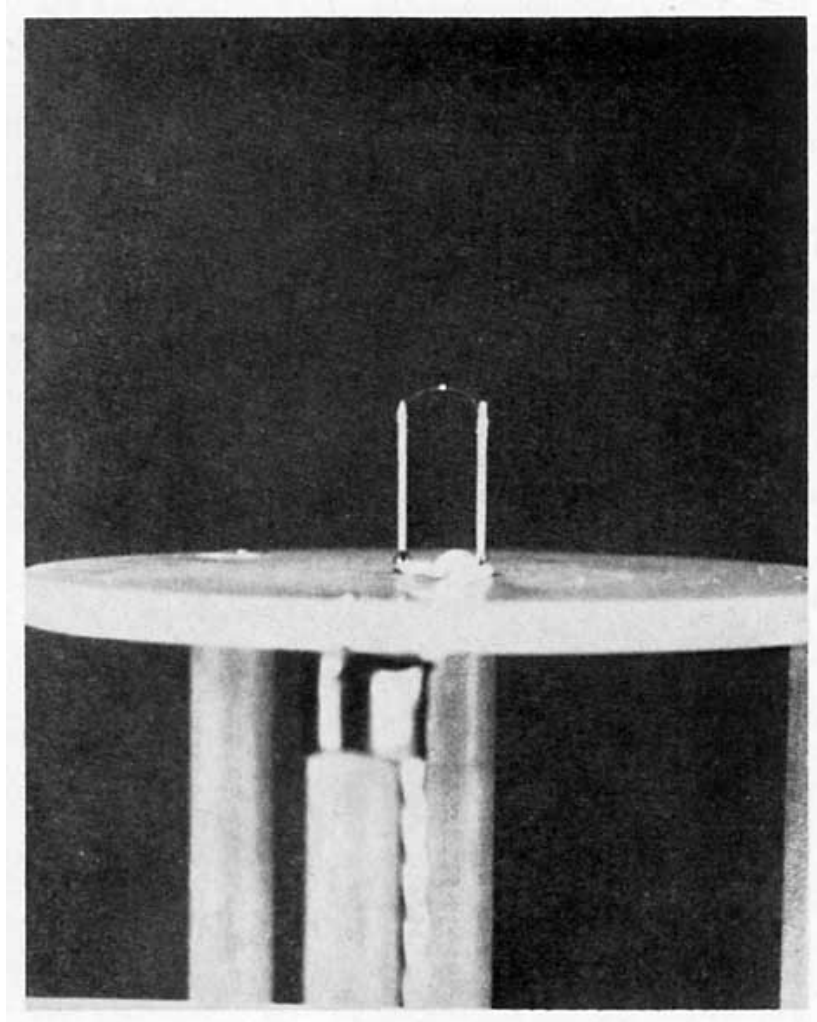

FIG. 3. Delta-I temperature sonde thermistor mount.

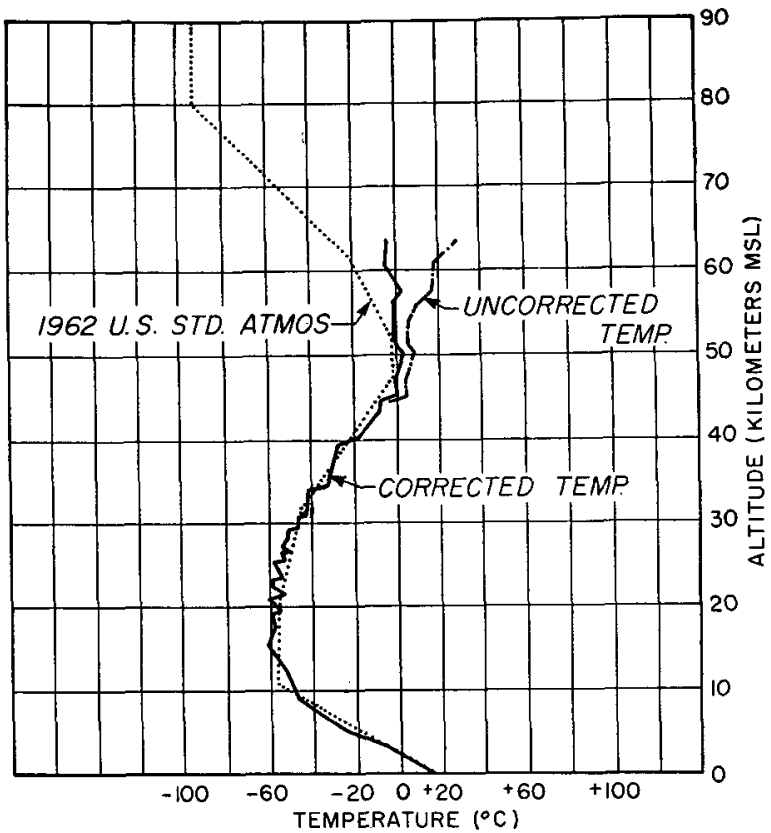

STATION_WSMR, N.M.

ROCKET TYPE ARCAS OELTA / INST

DATE IT FEB 1965 TIME OOIOZ (1710 MST - 16/h)

FIG. 4. Temperature-altitude profile, Delta-I temperature sonde, showing uncorrected and corrected temperatures (Table 1).

2) A net gain of energy per unit time of $15 \mu \mathrm{W}$ caused by solar radiation. (No account was taken of the radiation absorbed by the thermistor leads.)

3) A net gain of energy per unit time of $160 \mu \mathrm{W}$ caused by heat conduction from the thermistor mounting posts. (No consideration was given here to the convective heat transfer from the mounting posts to the surrounding atmosphere.)

4) A net transfer of energy per unit time by convection of $5 \mu \mathrm{W}$ per degree temperature difference between the thermistor and the surrounding atmosphere. [The convective heat transfer coefficient $h_{t}=4 \times 10^{-4} \mathrm{cal} \mathrm{cm}^{-2}$ $\mathrm{sec}^{-1}\left({ }^{\circ} \mathrm{K}\right)^{-1}$ is based upon the work of Barr (1961).]

5) An aerodynamic-heating air temperature increase of 15.0C. (Recovery factor $r=1.10$, fall velocity $v=165$ $\mathrm{m} \mathrm{sec}^{-1}$.)

6) An electrical-heating thermistor temperature increase of $7.8 \mathrm{C}$. [Electrical power dissipation $W=70$ $\mu \mathrm{W}$, dissipation factor $S_{t}=9 \mu \mathrm{W}\left({ }^{\circ} \mathrm{K}\right)^{-1}$.]

If it is assumed that the thermistor remains at an altitude in the neighborhood of $65 \mathrm{~km}$ for a time longer than the response time $\tau_{t}$ of the thermistor, then the rates of input energy to the thermistor listed in 1)-3) above would correspond to a lowering of the thermistor temperature by $0.3 \mathrm{C}$ due to the long wave radiation, an increase in the thermistor temperature of approximately $1.7 \mathrm{C}$ due to solar radiation, and an increase in the thermistor temperature of $17.8 \mathrm{C}$ due to heat conduction from the thermistor supports. 
These values for the changes in the thermistor temperature were determined by the thermistor dissipation factor. Expressions for the dissipation factor $S_{t}$ and the time constant $\tau_{t}$ are developed in Eqs. (2.1) through (2.7).

Let the modes of energy transfer be those of radiation $R$, conduction $H_{c d}$, convection $H_{c v}$, plus an incremental input of electrical energy $E$. Let the initial conditions be such that a thermal steady state has been reached for all processes with electrical energy input $E_{1}$, thermistor temperature $T_{1}=T_{e}+T_{01}$, where $T_{e}$ is the environment temperature, $T_{01}$ the temperature increment due to electrical heating, and $T_{s}$ the support post temperature $\left(=T_{e}\right)$. Let the conditions be changed such that electrical energy $E_{2}>E_{1}$ is added to the thermistor resulting in the thermistor temperature coming to a new equilibrium value $T_{2}=T_{e}+T_{02}>T_{1}$, all other external conditions remaining the same. The thermistor dissipation factor is experimentally determined by this method. Then,

$$
\begin{gathered}
\begin{array}{c}
d T_{1} \\
m c \frac{d E_{1}}{d t}
\end{array}=\frac{d R_{1}}{d t}+\frac{d H_{c d 1}}{d t}+\frac{d H_{c v 1}}{d t}=0 \\
m c \frac{d T_{2}}{d t}=\frac{d E_{2}}{d t}+\frac{d R_{2}}{d l}+\frac{d H_{c d 2}}{d t}+\frac{d H_{c v 2}}{d t}=0 .
\end{gathered}
$$

Let $P_{2}=d E_{2} / d t$ and $P_{1}=d E_{1} / d t$ (the electrical thermistor power). Subtracting (2.1) from (2.2),

$$
\begin{aligned}
P_{2}-P_{1}=-\left[\frac{d}{d t}\left(R_{2}-R_{1}\right)+\frac{d}{d t}\right. & \left(H_{c d 2}-H_{c d 1}\right) \\
& \left.+\frac{d}{d t}\left(H_{c v 2}-H_{c v 1}\right)\right] .
\end{aligned}
$$

Substitution of the expressions for the rates of heat transfer by conduction, convection, and radiation with $T=T_{e}+T_{0}$ and $T_{0} \ll T_{e}$ gives

$$
\begin{aligned}
P_{2}-P_{1}= & -\left\{\left[\sigma A T_{e}{ }^{4}-\sigma A\left(T_{e}+T_{02}\right)^{4}\right]\right. \\
& -\left[\sigma A T_{e}{ }^{4}-\sigma A\left(T_{e}+T_{01}\right)^{4}\right] \\
& +\frac{2 K \beta}{X}\left[T_{s}-\left(T_{e}+T_{02}\right)\right] \\
& -\frac{2 K \beta}{X}\left[T_{s}-\left(T_{e}+T_{01}\right)\right]+h A\left[T_{e}-\left(T_{e}+T_{02}\right)\right] \\
& \left.\quad-h A\left[T_{e}-\left(T_{e}+T_{01}\right)\right]\right\} . \quad \text { (2.4) }
\end{aligned}
$$


DELTA I ROCKETSONDE-ALTITUDE $65 \mathrm{KM}$

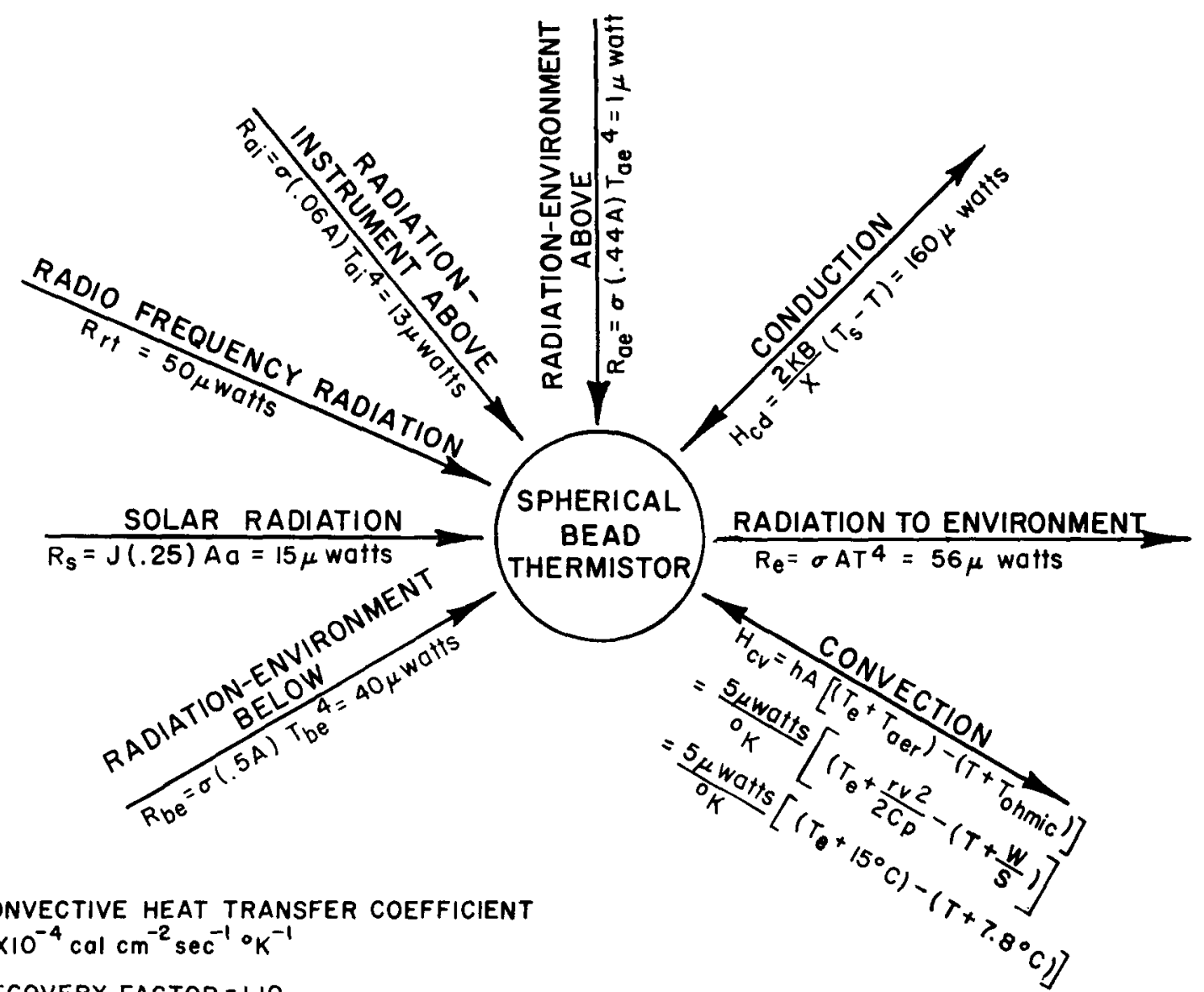

h-CONVECTIVE HEAT TRANSFER COEFFICIENT

$=4 \times 10^{-4} \mathrm{cal} \mathrm{cm}^{-2} \mathrm{sec}^{-1}{ }^{\circ} \mathrm{K}^{-1}$

$r$-RECOVERY FACTOR $=1.10$

$\checkmark$-FALL VELOCITY $=165 \mathrm{~m} / \mathrm{seC}$

$C_{P}$-SPECIFIC HEAT OF AIR (CONSTANT PRESSURE)

$=1.0 \times 10^{7} \mathrm{~cm}^{2} \mathrm{sec}^{-2} 0_{\mathrm{K}} \mathrm{K}^{-1}$

W-ELECTRICAL POWER ACROSS THERMISTOR

$T_{\text {De }}$-TEMPERATURE OF ENVIRONMENT BELOW Toe-TEMPERATURE OF ENVIRONMENT ABOVE $=70 \mu$ Wolts

$\frac{1}{S}$ - CHANGE IN TEMPERATURE $/ \mu$ watts OF POWER $=.16{ }^{\circ} \mathrm{C} / \mu$ watts

$T_{a i}$-TEMPERATURE OF INSTRUMENT ABOVE

$J_{1}$-SOLAR CONSTANT $=.045 \mathrm{col} \mathrm{cm}^{-2} \mathrm{sec}^{-1}(\mathrm{~J}+35 \%)$

$\sigma$-STEFAN BOLTZMANN CONSTANT

A-THERMISTOR SURFACE AREA $=3.22 \times 10^{-3} \mathrm{~cm}^{2}$ a-ABSORPTION COEFFICIENT FOR ALUMINUM $=.1$

$T_{\text {aer }}=\frac{r v^{2}}{2 c_{p}} \quad T_{\text {ohmic }}=\frac{w}{s}$

$T$-THERMISTOR TEMPERATURE

$T_{8}$ - THERMISTOR SUPPORT TEMPERATURE $T_{0}$ - TEMPERATURE OF IMMEDIATE ENVIRONMENT

K-THERMAL CONDUCTIVITY OF LEAD WIRE $=.074 \mathrm{col} \mathrm{cm}^{-1} \mathrm{sec}^{-1}{ }^{\circ} \mathrm{K}^{-1}$

$\beta$-CROSS-SECTIONAL AREA OF LEAD WIRE $=5.1 \times 10^{-6} \mathrm{~cm}^{2}$

$X$ - LENGTH OF LEAD WIRE $=1 \mathrm{~cm}$

C-SPECIFIC HEAT OF THERMISTOR $=.18 \mathrm{col} \mathrm{gm}^{-1} \otimes_{\mathrm{K}}^{-1}$

$M$-THERMISTOR MASS $=3.9 \times 10^{-5} \mathrm{gm}$ $S=\left[4 \sigma A T_{0}^{3}+\frac{2 K B}{X}+h A\right]$ T- TIME CONSTANT $=\frac{\mathrm{mC}}{\mathrm{S}}=3.1 \mathrm{sec}$

FIG. 5. Principal modes of heat transfer for rocketsonde thermistor. 
With the approximation that $T_{0} \ll T_{e}$, the above expression simplifies to

$$
\begin{aligned}
P_{2}-P_{1}=4 \sigma A T_{e}{ }^{3}\left(T_{02}-T_{01}\right) & \\
& +\frac{2 K \beta}{X}\left(T_{02}-T_{01}\right)+h A\left(T_{02}-T_{01}\right) .
\end{aligned}
$$

The dissipation factor $S_{i}$ then becomes

$$
S_{t}=\frac{P_{2}-P_{1}}{T_{02}-T_{01}}=4 \sigma A T_{e}{ }^{3}+\frac{2 K \beta}{X}+h A .
$$

The time constant $\tau_{t}$ is given by the expression $m_{t} c_{t} / S_{t}$. Thus,

$$
\tau_{t}=-\frac{m_{t} c_{t}}{4 \sigma A_{t} T_{e}{ }^{3}+\frac{2 K \beta}{X}+h A} .
$$

The term $4 \sigma A_{t} T_{e}{ }^{3}$ gives the rate of energy transfer per degree Kelvin by long wave radiation, the term $2 K \beta / X$ is the heat transfer rate per degree Kelvin due to conduction along the thermistor leads between the thermistor and the thermistor support, while the term $h_{t} A_{t}$ gives the rate of heat transfer per degree Kelvin by forced convection. Substituting the numerical values of the various quantities for the Delta-I instrument at $65 \mathrm{~km}$ (Fig. 5) gives the values of 1,3 , and $5 \mu \mathrm{W}$ $\left({ }^{\circ} \mathrm{K}\right)^{-1}$ for the heat transfer processes of radiation, conduction, and forced convection, respectively. The sum of these three values gives a dissipation factor $S_{t}=9$ $\mu \mathrm{W}\left({ }^{\circ} \mathrm{K}\right)^{-1}$ at $65 \mathrm{~km}$, where $S_{\ell}$ is the dissipation factor for the thermistor as mounted on the Delta-I instrument.

A sum of the various temperature differences between the thermistor and the surrounding air as caused by aerodynamic and electrical heating, long wave and solar radiation, and heat conduction from the thermistor mounts indicates that the thermistor temperature would exceed that of its environment by approximately $36 \mathrm{~K}$ at an altitude of $65 \mathrm{~km}$. This is approximately the same value as that obtained by Wagner at an altitude of $65 \mathrm{~km}$ with an instrument expulsion altitude of $70 \mathrm{~km}$.

Solution of the time dependent heat transfer equation shows that the time constant $\tau_{t}$ of the thermistor is given by the quantity $m_{t} c_{t} / S_{t}$ where $m_{t}$ and $c_{t}$ are the mass and specific heat of the thermistor, respectively. $\tau_{t}$ is simply the ratio of the heat energy absorbed by the thermistor per degree Kelvin to the rate of energy transfer per degree Kelvin.

The calculated value of the time constant $\tau_{t}$ for the Delta-I thermistor at an altitude of $65 \mathrm{~km}$ is $3.1 \mathrm{sec}$ with $m_{t}=3.9 \times 10^{-5} \mathrm{gm}, c_{t}=0.18 \mathrm{cal} \mathrm{gm}^{-1}\left({ }^{\circ} \mathrm{K}\right)^{-1}$, and $S_{t}=9 \mu \mathrm{W}\left({ }^{\circ} \mathrm{K}\right)^{-1}$. In a time of $3.1 \mathrm{sec}$, the thermistor falls approximately $0.5 \mathrm{~km}$ indicating that the assumption of the thermistor remaining at an altitude close to $65 \mathrm{~km}$ for a time longer than the response time of the thermistor is not valid; however, the numerical values for the various sources of energy input serve to indicate the most significant sources of temperature difference between the thermistor and the atmosphere at an altitude of $65 \mathrm{~km}$.

\section{Rocketsonde redesign}

Consideration of the heat transfer equations and an experimental analysis of the physical, thermodynamic and electrical characteristics of the Delta-I rocketsonde indicated that the theoretically predicted temperature differences between the thermistor and the kinetic temperatures of the stratosphere could be substantially reduced. The rocketsonde was redesigned by:

1) Changing the thermistor mounting post configuration and placing a heat sink (time constant less than that of the thermistor) between the thermistor and the instrument body, shortening the thermistor leads to a minimum length consistent with attachment to the heat sink, and by reducing the mass-to-area ratio of the mount plate.

2) Matching the exponential resistance-temperature characteristic of the bead thermistor to the exponential resistance-modulation frequency characteristic of the instrument electronics to produce a modulation frequency which is a linear function of the thermistor temperature and which gives an optimum temperature resolution in the range -65 to $+30 \mathrm{C}$ :

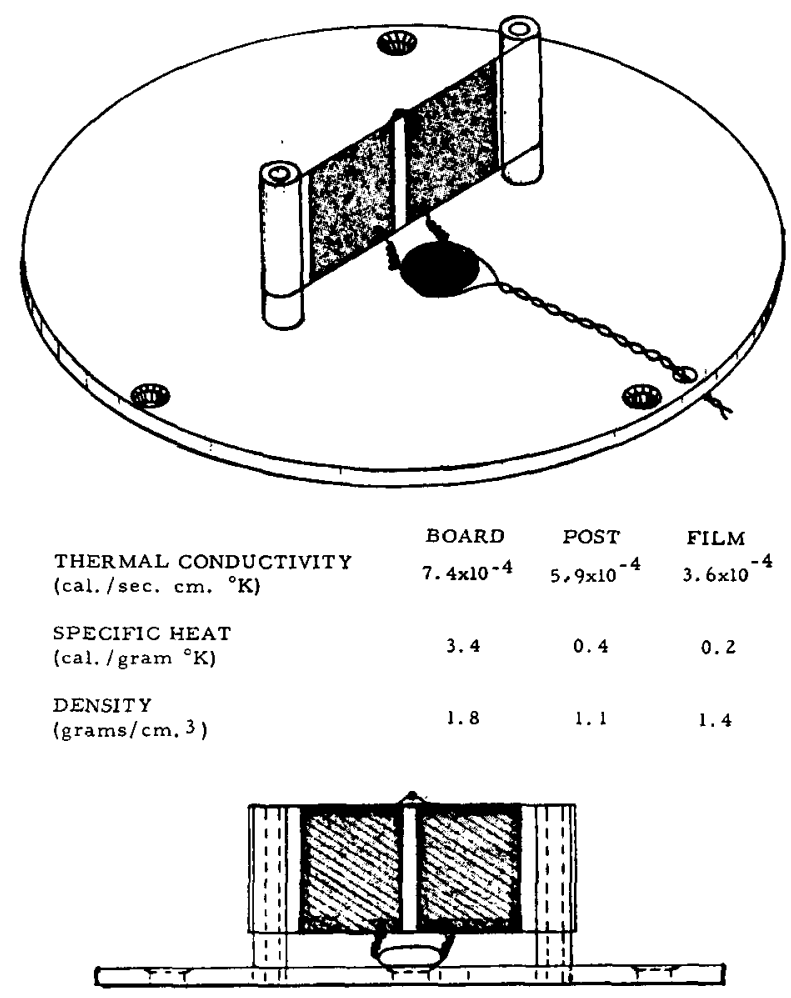

Fig. 6. Thermistor mount, STS-1 instrument. 
3) Reducing the electrical power dissipated in the thermistor such that the temperature error due to ohmic heating is negligible.

a) The thermistor mount. The thermistor mounting configuration is shown in the drawing of Fig. 6. The dimensions of the thermistor mount were chosen so as to give a maximum height and width consistent with insuring that the thermistor and mount could not be swept off by the nose cone at the time of instrument expulsion. The thermistor mount is constructed from a commercially available mylar polyester aluminized film $1 \times 10^{-3} \mathrm{~cm}$ thick which is stretched between two hollow cylindrical support posts of type 6/6 nylon tubing, 3.2 $\mathrm{mm}$ outside diameter. The support post wall thickness is that giving a minimum mass-to-area ratio consistent with giving sufficient strength to support the film and thermistor at the time of maximum stress during rocket launch and instrument expulsion. The thickness of the thermistor mount plate was also reduced to a minimum value consistent with necessary rigidity and strength. It is made from woven glass fabric and epoxy resin, Mil. Spec. Mil-P-18177C Type GEE. The thermal conductivity, specific heat, and density of the mylar, nylon tubing, and glass fabric are given in Fig. 6 . The mounting posts are glued into holes drilled in the mounting plate.

The aluminum coating of the mylar is removed with a sodium hydroxide solution after the film is properly masked, thus producing insulating strips at the center and at the two edges of the film mount. The mylar film is then stretched between the posts and secured by means of an epoxy glue. The leads of the thermistor ( $3 \mathrm{~mm}$ in length) are joined to the top edge of the mylar film mount, one on each side of the center insulating strip. They are joined to the film by inserting the end of each thermistor lead into a tiny hole which is punched through the mylar and are then secured in place by a small amount of silver paint. The electrical connections to the modulator circuit of the instrument package are secured to the lower edge of the film in a similar manner. A small capacitor $(0.001 \mu \mathrm{F})$ is connected so as to shunt the radio-frequency voltage which is induced in the leads by the field of the transmitter tube. The thermistor, mount, and mount plate are then secured to the instrument so that the thermistor is at a null point of the radio frequency field, thus minimizing the heating of the thermistor bead due to the absorption of radio frequency energy from the instrument transmitter.

From considerations identical to those for the dissipation factor $S_{t}$ of the bead thermistor, the expression for the dissipation factor for the mylar film mount is

$$
S_{f}=4 \sigma A_{f} T_{e}^{3}+\frac{2 k \alpha}{w}+h_{f} A_{f},
$$

the three terms on the right having values of 2000,3 and $3200 \mu \mathrm{W}\left({ }^{\circ} \mathrm{K}\right)^{-1}$, respectively, for a total of approximately $5200 \mu \mathrm{W}\left({ }^{\circ} \mathrm{K}\right)^{-1}$. In (3.1),

$A_{f}$ is the film area $\left(=3.2 \mathrm{~cm}^{2}\right)$,

$k$ is the thermal conductivity of mylar $\left[=3.6 \times 10^{-4}\right.$ cal sec$\left.{ }^{-1} \mathrm{~cm}^{-1}\left({ }^{\circ} \mathrm{K}\right)^{-1}\right]$,

$\alpha$ is the cross-sectional area of the film $\left(=1.3 \times 10^{-3}\right.$ $\mathrm{cm}^{2}$; thickness, $1 \times 10^{-3} \mathrm{~cm}$, height, $1.3 \mathrm{~cm}$ ),

$w$ is the halfwidth of the film from post to film center $(=1.3 \mathrm{~cm})$,

$h_{f}$ is the convective heat transfer coefficient for the film $\left[=1.3 \times 10^{-4} \mathrm{cal}^{-1} \mathrm{~cm}^{-2} \mathrm{sec}^{-1}\left({ }^{\circ} \mathrm{K}\right)\right.$ at $65 \mathrm{~km}$ (Ramsdale, 1965)], $\sigma=1.38 \times 10^{-12} \mathrm{cal} \mathrm{sec}^{-1} \mathrm{~cm}^{-2}\left({ }^{\circ} \mathrm{K}\right)^{-4}$, and

$T_{e}$ is the environmental temperature $(=240 \mathrm{~K}$ at 65 $\mathrm{km})$.

The values of each term of Eq. (3.1) are based upon the above numerical values and are applicable to the film at an altitude of $65 \mathrm{~km}$.

The corresponding time constant for the film is given by the expression

$$
\tau_{f}=\frac{m_{f} c_{f}}{S_{f}}=\frac{m_{f} c_{f}}{4 \sigma A_{f} T_{e}{ }^{3}+\frac{2 k \alpha}{w}+h_{f} A_{f}},
$$

where

$m_{f}$ is the film mass $\left(=\rho_{f} A_{f} t_{f}=4.5 \times 10^{-3} \mathrm{gm}\right)$, $\rho_{f}$ is the film density $\left(=1.4 \mathrm{gm} \mathrm{cm}^{-3}\right)$,

$A_{f}$ is $3.2 \mathrm{~cm}^{2}$,

$t_{f}$ is the film thickness $\left(=1 \times 10^{-3} \mathrm{~cm}\right)$, and

$c_{f}$ is the film specific heat $\left[=0.2 \mathrm{cal} \mathrm{gm}^{-1}\left({ }^{\circ} \mathrm{K}\right)^{-1}\right]$.

Based upon the above values the quantity $m_{f} c_{f}$ has a value of $3.6 \times 10^{-3} \mathrm{~J}\left({ }^{\circ} \mathrm{K}\right)^{-1}$ and the time constant of the film at an altitude of $65 \mathrm{~km}$ is

$$
\tau_{f}=\frac{m_{f} c_{f}}{S_{f}}=\frac{3.6 \times 10^{-3} \mathrm{~J}\left({ }^{\circ} \mathrm{K}\right)^{-1}}{5.2 \times 10^{-3} \mathrm{~J} \mathrm{sec}^{-1}\left({ }^{\circ} \mathrm{K}\right)^{-1}}=0.7 \mathrm{sec} .
$$

The value of $0.7 \mathrm{sec}$ for the time constant of the film mount is less than the value of $3.1 \mathrm{sec}$ for the time constant of the Delta-I mounted thermistor at an altitude of $65 \mathrm{~km}$. Thus, the film will more rapidly come to temperature equilibrium with its environment than does the thermistor. If the temperature sensing instrument is ejected from the rocket nose cone (temperature $=370 \mathrm{~K}$ ) into an environment whose temperature is in the neighborhood of $220 \mathrm{~K}$, then the temperature of the film mount will, at times shortly after ejection, be lower than that of the thermistor and heat energy will be conducted from the bead to the film. The reduction of the thermistor lead lengths from approximately $1 \mathrm{~cm}$ in the Delta $I$ instrument to $X_{m}=0.3 \mathrm{~cm}$ as they are attached to the mylar film in the new design accounts for a change in the value of the quantity $2 K \beta / X$ from 3 to $10 \mu \mathrm{W}\left({ }^{\circ} \mathrm{K}\right)^{-1}$. The expression for dissipation factor 
$S_{t m}$ of the thermistor on the mylar film support becomes

$$
S_{t m}=4 \sigma A_{t} T_{e}{ }^{3}+\frac{2 K \beta}{X_{m}}+h_{t} A_{t},
$$

the three terms on the right having values of 1,10 , and $5 \mu \mathrm{W}\left({ }^{\circ} \mathrm{K}\right)^{-1}$, respectively, for a total of $16 \mu \mathrm{W}\left({ }^{\circ} \mathrm{K}\right)^{-1}$. The corresponding thermistor time constant $\tau_{t m}=m_{t} c_{t}$ ) $S_{t m}=1.8 \mathrm{sec}$. The value of $16 \mu \mathrm{W}\left({ }^{\circ} \mathrm{K}\right)^{-1}$ for the dissipation factor $S_{i m}$ of the thermistor on the mylar mount compares with $9 \mu \mathrm{W}\left({ }^{\circ} \mathrm{K}\right)^{-1}$ for the Delta-I instrument (Fig. 3).

Since the time constant $\tau_{f}$ for the mylar film of 0.7 sec is less than the time constant $\tau_{t m}$ of $1.8 \mathrm{sec}$ for the film-mounted thermistor, heat energy is transferred by conduction from the thermistor to the film mount at the rate of $10 \mu \mathrm{W}$ per degree temperature difference between the thermistor and the mount shortly after instrument ejection at $70 \mathrm{~km}$. This energy is then dissipated from the film at the rate of $5200 \mu \mathrm{W}\left({ }^{\circ} \mathrm{K}\right)^{-1}$ by the heat transfer processes of radiation and convection. Reference to Fig. 5 indicates that energy was transferred by conduction from the mounting posts to the thermistor at the rate $3 \mu \mathrm{W}\left({ }^{\circ} \mathrm{K}\right)^{-1}$ at an altitude of $65 \mathrm{~km}$ in the Delta-I system.

To determine the possible maximum rate of transfer of heat energy by conduction from the nylon mounting posts to the mylar film, it was assumed that the center of the film had come to temperature equilibrium with the environment at $65 \mathrm{~km}(240 \mathrm{~K})$, while the posts had remained at the nose cone temperature at the time of ejection (370K). The value of $2 k \alpha / w$ from Eq. (3.1) is $3 \mu \mathrm{W}\left({ }^{\circ} \mathrm{K}\right)^{-1}$. Thus, for the temperature difference assumed, the rate of energy transfer by conduction would be $390 \mu \mathrm{W}$. The dissipation factor for the film was shown to be $5200 \mu \mathrm{W}\left({ }^{\circ} \mathrm{K}\right)^{-1}$. The temperature of the film due to conduction under the above assumed conditions would increase by approximately $0.1 \mathrm{~K}$, indicating that the thermistor and mount are essentially isolated from the instrument body relative to heat transfer by conduction.

To determine the possible maximum rate of heat transfer due to solar radiation and the corresponding maximum temperature change in the bead thermistor, it was assumed that the plane of the mylar film mount was perpendicular to the direction of propagation of the solar radiation and that the thermistor and film were in temperature equilibrium at the time of solar energy incidence. Based upon the values, $J=0.045 \mathrm{cal}$ $\mathrm{sec}^{-1} \mathrm{~cm}^{-2}, A_{f}=3.2 \mathrm{~cm}^{2}$, and $a=0.05$, the rate of absorption of solar energy by the film would be $J A_{f} a$ $=28,800 \mu \mathrm{W}$. The value of the solar constant was increased by a factor of 35 per cent to account for reflections from cloud structures. A similar calculation for the bead thermistor indicated a rate of solar energy absorption of $15 \mu \mathrm{W}$. The dissipation factors for the mylar film mount and thermistor were shown to be 5200 and $16 \mu \mathrm{W}\left({ }^{\circ} \mathrm{K}\right)^{-1}$, respectively. Thus, the temper- ature of the film would increase by $5.5 \mathrm{~K}$ in a time of $0.7 \mathrm{sec}$, while the temperature of the thermistor would increase by $1.0 \mathrm{~K}$ in a time of $1.8 \mathrm{sec}$ due to direct solar radiation. A temperature difference of $4.5 \mathrm{~K}$ would then exist between the mylar film and the thermistor with an attendant rate of transfer of energy by conduction from the film to the thermistor of $45 \mu \mathrm{W}$ [based on $10 \mu \mathrm{W}\left({ }^{\circ} \mathrm{K}\right)^{-1}$ from Eq. (3.4)]. The corresponding temperature increase of the thermistor would then be approximately $3 \mathrm{~K}$ based on a thermistor dissipation constant of $16 \mu \mathrm{W}\left({ }^{\circ} \mathrm{K}\right)^{-1}$. Thus, the maximum temperature increase of the thermistor due to solar radiation would be approximately $4 \mathrm{~K}$ under the above assumed conditions.

This estimate of the temperature increase caused by solar radiation is probably extreme. The period of oscillation of the parachute is approximately $5 \mathrm{sec}$, with an angular swing amplitude of $45 \mathrm{deg}$ relative to a vertical line (Beyers et al., 1962). If the thermistor and mount are exposed to direct solar radiation for a period of time and are then shaded by the rocketsonde instrument or parachute for a time as great as $0.7 \mathrm{sec}$, the mylar film thermistor mount will return to the temperature of the surrounding atmosphere with an attendant transfer of solar heat energy by conduction from the thermistor to the thermistor mount accompanied by a reduction in the thermistor temperature. If the thermistor and mount are shaded for a period of time as great as $1.8 \mathrm{sec}$, both return to the air temperature. Temperature oscillations with peak-to-peak magnitudes of the order of $5 \mathrm{C}$ have been observed with rocketsonde instruments which make use of clear mylar film as the mounting material. The coldest temperature recorded during the oscillation is taken as the environmental temperature when the temperature data are reduced.

The absorption factor of 0.05 for the $0.001 \mathrm{~cm}$ thick mylar film thermistor mount was determined on the basis of the transmissivity-wavelength recording shown in Fig. 7 for a sample of uncoated mylar. The film as utilized for the mount in the newly designed instrument is coated with aluminum (400 $\AA$ thickness) which

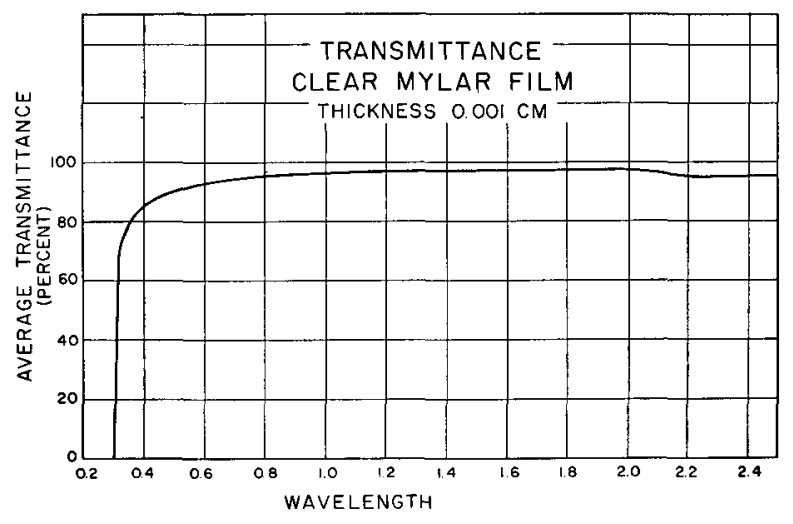

FIG. 7. Transmissivity vs. wavelength of the Mylar film. Wavelength is in microns. 
has a reflection coefficient of 0.90 , thus giving a resultant extinction coefficient for the aluminum coated mylar mount of the order of $5 \times 10^{-3}$. The rate of absorption of solar energy by the film is then approximately 2880 $\mu \mathrm{W}$ while the thermistor absorbs energy at the rate of $15 \mu \mathrm{W}$. The corresponding temperature rise of the film is $0.6 \mathrm{~K}\left[S_{f}=5200 \mu \mathrm{W}\left({ }^{\circ} \mathrm{K}\right)^{-1}\right]$ in a time of $0.7 \mathrm{sec}$ while the increase in the thermistor temperature is $1.0 \mathrm{~K}$ in a time of $1.8 \mathrm{sec}\left[S_{t m}=16 \mu \mathrm{W}\left({ }^{\circ} \mathrm{K}\right)^{-1}\right]$. Based upon these calculations, the change in the temperature of the thermistor would be less than $1 K$ due to the absorption of solar radiation when an aluminum coated mylar film mount is utilized.

b) Matching of thermistor and instrument character- istics. To obtain an optimum temperature resolution in the range from -65 to $+30 \mathrm{C}$, the exponential resistance-temperature characteristic of the bead thermistor was matched to the exponential resistance-modulation frequency characteristic of the instrument electronics. The criterion followed for obtaining optimum temperature resolution is the result of the following mathematical development which indicates that the change in modulation frequency is directly proportional to the change in temperature, the constant of proportionality being the ratio of the slope of the resistance-temperature characteristic of the thermistor to the slope of the resistance-frequency characteristic of the instrument.

Let $T$ be the thermistor temperature, $R$ the thermistor

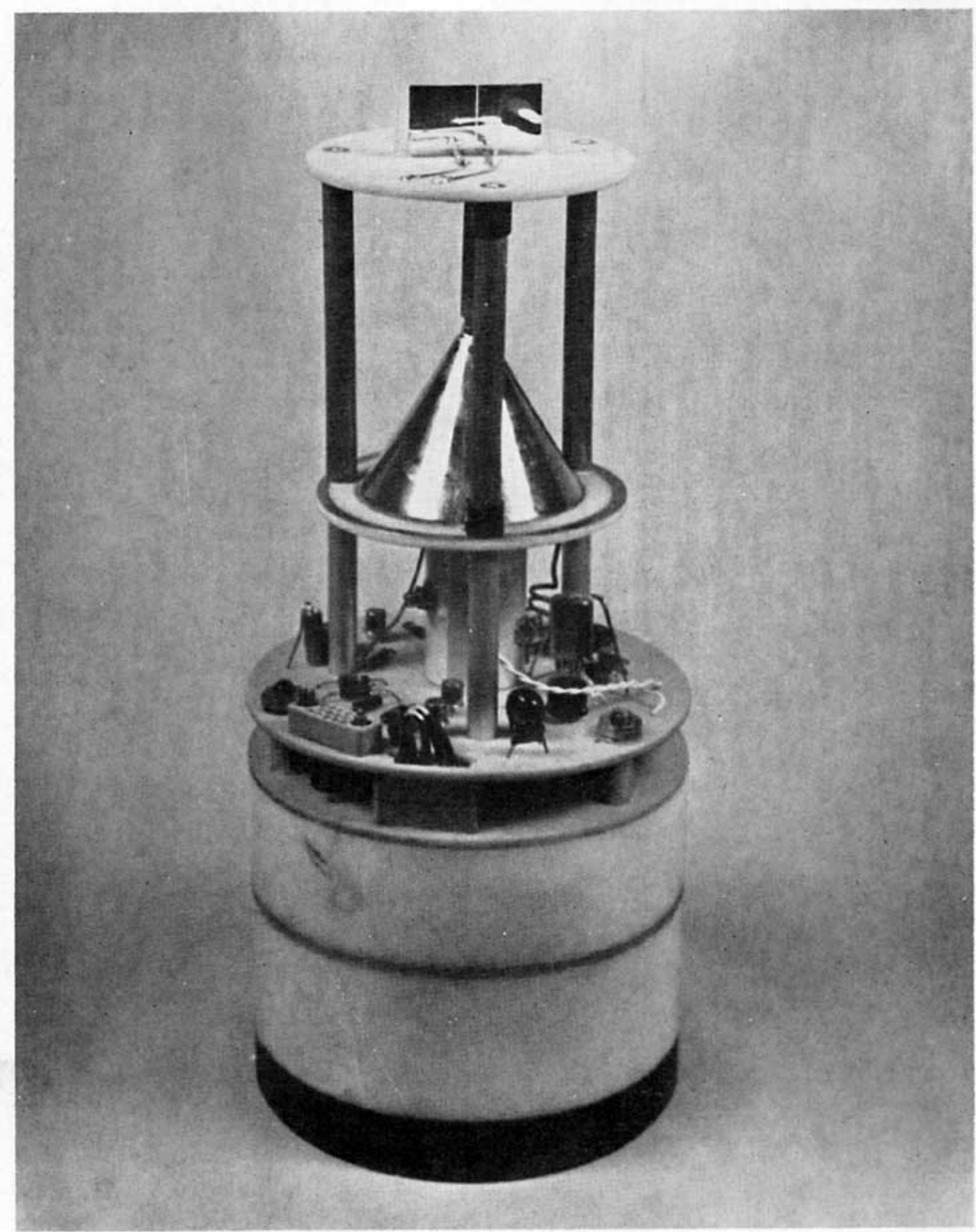

FIG. 8. Stratospheric temperature sonde,_STS-1. 


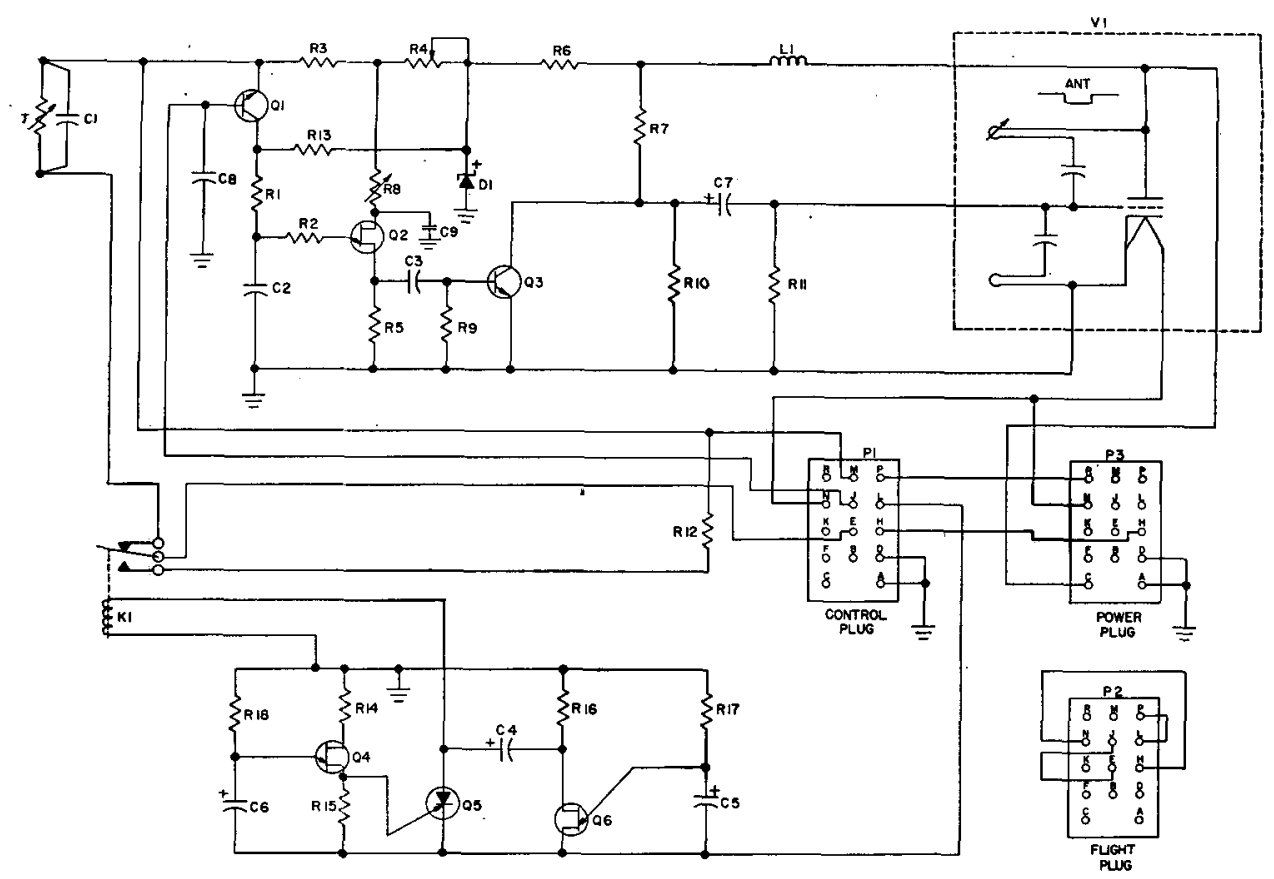

FIG. 9. Electrical circuit diagram for stratospheric temperature sonde, STS-1.

resistance, $f$ the modulation pulse frequency, $a$ the slope of the instrument resistance-frequency curve, and $\alpha$ the slope of the thermistor resistance-temperature curve. Then for the rocketsonde instrument,

$$
\ln R=-a f+\ln A \text { and } R=A e^{-a f} .
$$

The boundary conditions that $f=f_{0}$ and $R=R_{0}$ lead to

$$
R=R_{0} e^{-\alpha\left(f-f_{0}\right)} \text {. }
$$

For the thermistor,

$$
\ln R=-\alpha T+\ln B \text { and } R=B e^{-\alpha T} .
$$

The boundary conditions that $T=T_{0}$ when $R=R_{0}$ lead to

$$
R=R_{0} e^{-\alpha\left(T-T_{0}\right)} \text {. }
$$

Combining Eqs. (3.6) and (3.8) gives

$$
R=R_{0} e^{-a\left(f-f_{0}\right)}=R_{0} e^{-\alpha\left(\mathrm{T}-\mathrm{T}_{0}\right)}
$$

leading to

$$
f-f_{0}=\frac{\alpha}{a}-\left(T-T_{0}\right) \text { and } d f=\frac{\alpha}{a} d T .
$$

Therefore, a $1 \mathrm{~K}$ change in thermistor temperature will produce a change in modulation pulse frequency equal to or greater than 1 pulse $\sec ^{-1}$ as the ratio $\alpha / a>1$.

The rocketsonde instrument was redesigned such that $\alpha / a=1$ throughout the temperature range from -65 to $+50 \mathrm{C}$, thus producing a 1 pulse $\sec ^{-1}$ change in modulation frequency corresponding to a one degree Kelvin change in temperature over this interval. Changes in modulation frequency of the order of 0.4 pulse $\sec ^{-1}$ can be determined from the TMQ-5 recorder record with a corresponding temperature resolution of approximately $0.4 \mathrm{C}$.

c) Characteristics of the new design. The physical and electrical characteristics of the new STS-1 stratospheric temperature sonde are shown in the photograph of Fig. 8 and in the schematic diagram of Fig. 9, respectively. Fig. 10 gives the thermistor resistance-temperature characteristics of the Gulton $42.5 \mathrm{CX} 21$ thermistor and the modulation frequency-thermistor resistance characteristic of the new instrument. Both graphs have essentially the same slope throughout the temperature region of interest, thus giving the temperature resolu-

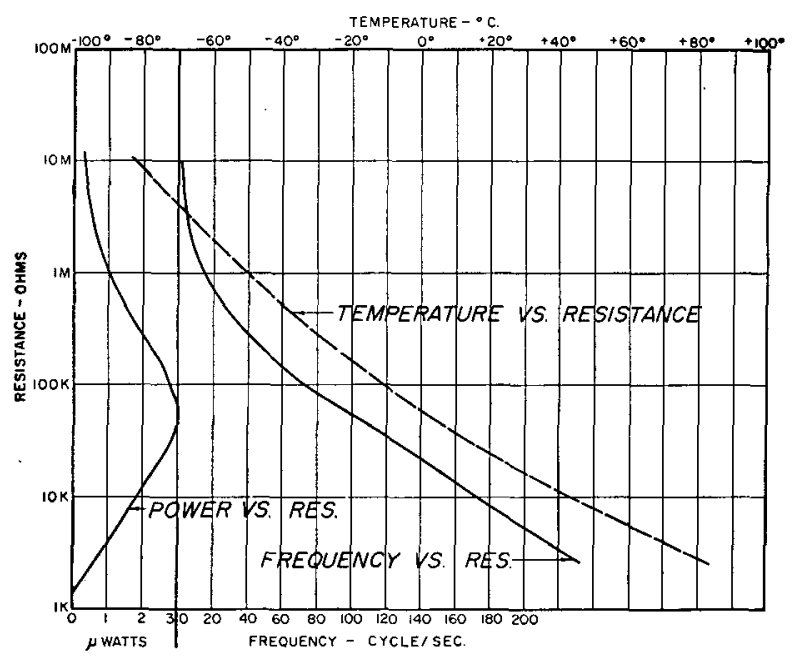

Fig. 10. Characteristic curves, STS-1 instrument. 
tion discussed in Section 3b. Also shown in Fig. 10 is the electrical power dissipated across the thermistor as a function of thermistor resistance which indicates that the power dissipated does not exceed $3 \mu \mathrm{W}$. The resultant temperature increase of the thermistor due to ohmic heating is, therefore, less than $0.2 \mathrm{C}[16 \mu \mathrm{W}$ $\left.\left({ }^{\circ} \mathrm{K}\right)^{-1}\right]$.

\section{Experimental results}

Fig. 11 is the temperature-time record as received by the GMD-1 meteorological receiver $(1680 \mathrm{Mc})$ and recorded by the TMQ-5 meteorological recorder. The temperature data were transmitted by the stratospheric temperature sonde STS-1 shown in Fig. 8. The following characteristics of the temperature-time record are perhaps of interest:

1) Rocket launch accompanied by an initial cooling of the air inclosed by the nose cone. The temperature decreases by $13 \mathrm{~K}$ in a time of approximately $10 \mathrm{sec}$, reaching a minimum value at an altitude of $3 \mathrm{~km}$. This cooling is presumed to be caused by an adiabatic expansion of the air from within the nose cone.

2) Subsequent rapid temperature rise in the rocket nose to $80 \mathrm{C}$ at a time $60 \mathrm{sec}$ after launch, followed by a cooling of the nose cone air to $70 \mathrm{C}$ at the time of instrument expulsion from the nose cone.

3) Instrument expulsion $131 \mathrm{sec}$ after launch time $(73 \mathrm{~km})$. The time rate of temperature change of the thermistor $d T / d t$ was $-0.44 \mathrm{~K} \mathrm{sec}-1$.

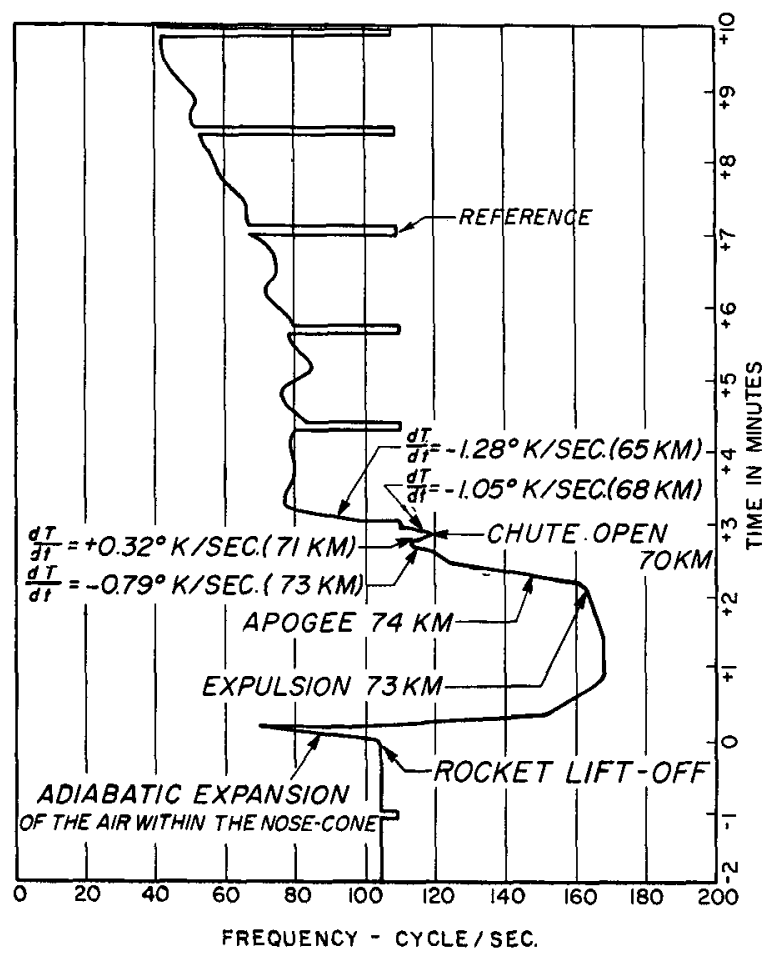

FIG. 11. Temperature-time record, STS-1 instrument.

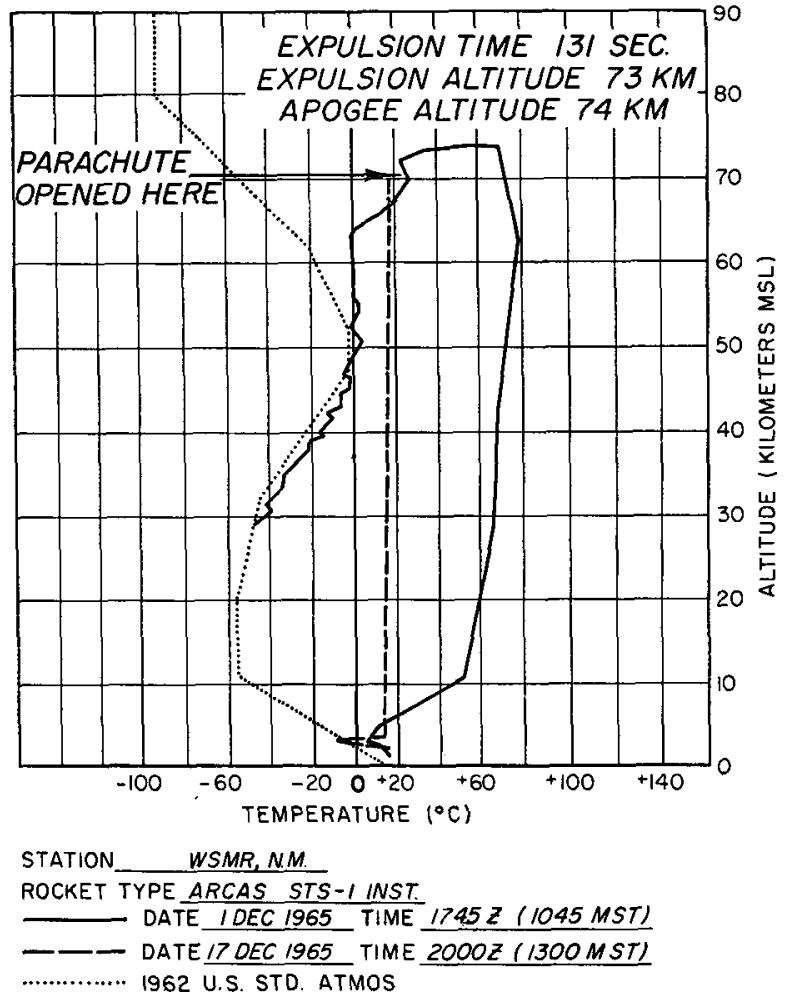

FIG. 12. Temperature-altitude profile from temperature-time record (see Fig. 11).

4) Instrument maximum altitude (apogee) $142 \mathrm{sec}$ after launch time $(74 \mathrm{~km})$, where $d T / d t$ was $-2.18 \mathrm{~K}$ $\mathrm{sec}^{-1}$, with fall speed equal to zero.

5) At time $157 \mathrm{sec}$ after launch time $(73 \mathrm{~km}) d T / d t$ was $-0.79 \mathrm{~K} \mathrm{sec}^{-1}$ with a fall speed of $137 \mathrm{~m} \mathrm{sec}^{-1}$; at time $167 \mathrm{sec}$ after launch $d T / d \ell$ was $+0.32 \mathrm{~K} \mathrm{sec}^{-1}$ with a fall speed of $215 \mathrm{~m} \mathrm{sec}^{-1}$.

6) In the time interval from 167 to $179 \mathrm{sec} d T / d t$ was $+0.32 \mathrm{~K} \mathrm{sec}^{-1}$. The fall speed changed from 215 to $325 \mathrm{~m} \mathrm{sec}^{-1}$. The position of the instrument changed from 71 to $69 \mathrm{~km}$.

7) At a time equal to $179 \mathrm{sec}$ after launch, the time rate of change of thermistor temperature reversed sharply to $-1.05 \mathrm{~K} \mathrm{sec}^{-1}$ from $+0.32 \mathrm{~K} \mathrm{sec}{ }^{-1}$. A correspondingly abrupt change occurred in the fall velocity [from 325 to $225 \mathrm{~m} \mathrm{sec}^{-1}$ ]. The radar plot of instrument position indicated the parachute opened at this time.

8) At a time $293 \mathrm{sec}$ after launch $(65 \mathrm{~km}) d T / d t$ was $-1.28 \mathrm{~K} \mathrm{sec}-1$. The fall velocity decreased to 170 $\mathrm{m} \mathrm{sec}-1$ and then continued to decrease to values of $120 \mathrm{~m} \mathrm{sec}^{-1}$ at $60 \mathrm{~km}$ and $70 \mathrm{~m} \mathrm{sec}^{-1}$ at $50 \mathrm{~km}$.

Fig. 12 is a temperature-altitude profile corresponding to the temperature-time record of Fig. 11. The points corresponding to the points of interest from the temperature-time record (1-8 above) are recognizable in the figure.

The dashed line in Fig. 12 shows the temperature- 
altitude record corresponding to the temperature-time record in which an insulating shield was placed around the STS-1 instrument thermistor and thin film mount in the rocket nose cone. The graph shows that the thermistor temperature did not exceed $+18 \mathrm{C}$ to the time of instrument expulsion. No data were received after instrument expulsion from this rocket flight.

\section{Analysis of the experimental results}

a) Thermistor convective heat transfer coefficient (experimental determination at $70 \mathrm{~km}$ ). The two previously described marked changes in the slope of the temperature-time record of Fig. 11 which occurred at times 167 and $179 \mathrm{sec}$ after launch time $(71 \mathrm{~km}-69 \mathrm{~km})$, served to determine the convective heat transfer coefficient of the bead thermistor at an altitude of $70 \mathrm{~km}$. The details of the calculation are as follows.

From the equations of heat transfer for the rocketsonde thermistor at altitudes of 71 and $69 \mathrm{~km}$, we have

$$
m_{t} c_{t} \frac{d T_{1}}{d t}=\frac{d R_{1}}{d t}+\frac{d H_{c d 1}}{d t}+\frac{d H_{c v 1}}{d t}+\frac{d S_{1}}{d t}
$$

and

$$
m_{t} c_{t} \frac{d T_{2}}{d l}=\frac{d R_{2}}{d l}+\frac{d H_{c d 2}}{d l}+\frac{d H_{c v 2}}{d l}+\frac{d S_{2}}{d t}
$$

where the subscripts 1 and 2 refer to the altitudes of $71 \mathrm{~km}$ and $69 \mathrm{~km}$, respectively. Let the space and time interval be such that the long wave and solar radiation terms remain constant, that is $d R_{1} / d t=d R_{2} / d t$ and $d S_{1} / d t=d S_{2} / d t$. The time interval is equal to $12 \mathrm{sec}$, the space interval is equal to $2 \mathrm{~km}$.

Subtracting (5.1a) from (5.1b) gives

$$
\begin{array}{r}
m_{t} c_{t}\left(\frac{d T_{2}}{d t}-\frac{d T_{1}}{d t}\right)=\frac{d}{d t}\left(H_{c d 2}-H_{c d 1}\right) \\
+\frac{d}{d t}\left(H_{c v 2}-H_{c v 1}\right) .
\end{array}
$$

Substituting the values for $H_{c d}$ and $H_{c v}$ to include the effects of aerodynamic heating with ohmic heating negligible yields

$$
m_{t} c_{t}\left(\frac{d T_{2}}{d t}-\frac{d T_{1}}{d t}\right)=\frac{2 K \beta}{X_{m}}\left[\left(T_{f 2}-T_{2}\right)-\left(T_{f 1}-T_{1}\right)\right]+h_{t} A_{t}\left\{\left[\left(T_{e 2}+\frac{r V_{2}^{2}}{2 c_{p}}\right)-T_{2}\right]-\left[\left(T_{e 1}+\frac{r V_{1}{ }^{2}}{2 c_{x}}\right)-T_{1}\right]\right\} .
$$

Assume that the temperature of the film at 71 and $69 \mathrm{~km}$ remains essentially constant, i.e., $T_{f 2}=T_{f 1}$. Then

$$
m_{t} c_{t}\left(\frac{d T_{2}}{d t}-\frac{d T_{1}}{d t}\right)=-\frac{2 K \beta}{X_{m}}\left[T_{2}-T_{1}\right]+h_{t} A_{t}\left\{\left[\left(T_{e 2}-T_{e 1}\right)-\left(T_{2}-T_{1}\right)\right]+\frac{r}{2 c_{p}}\left(V_{2}^{2}-V_{1}^{2}\right)\right\} .
$$

Solving Eq. (5.3) for the quantity $h_{\imath} A_{t}$ gives

$$
h_{t} A_{t}=\frac{m_{t} c_{t}\left(\frac{d T_{2}}{d t}-\frac{d T_{1}}{d t}\right)+\frac{2 K \beta}{X}\left(T_{2}-T_{1}\right)}{\left\{\left(T_{e 2}-T_{e 1}\right)-\left(T_{2}-T_{1}\right)+\frac{r}{2 c_{p}}\left(V_{2}^{2}-V_{1}^{2}\right)\right\}} .
$$

Substituting numerical values, we have

$$
h_{t} A_{t}=\frac{28[0.32+0.79]+10(3.2)}{10-3.2+1.19(30)}=1.43 \mu \mathrm{W}\left({ }^{\circ} \mathrm{K}\right)^{-1} .
$$

The numerical values in Eq. (5.5) are based upon data obtained from the temperature-time record (Fig. 11), the radar plot of the instrument position and from the U. S. 1962 Standard Atmosphere, i.e.,

$$
\begin{aligned}
\frac{d T_{2}}{d t} & =+0.32 \mathrm{~K} \mathrm{sec}^{-1}, & \frac{d T_{1}}{d t} & =-0.79 \mathrm{~K} \mathrm{sec} \mathrm{sec}^{-1}, \\
T_{e 2}-T_{e 1} & =10 \mathrm{~K}(71-69 \mathrm{~km}), & T_{2}-T_{1} & =3.2 \mathrm{~K}, \\
\frac{2 K \beta}{X_{m}} & =10 \mu \mathrm{W}\left({ }^{\circ} \mathrm{K}\right)^{-1}, & r & =1.19 \text { (from Wagner), } \\
V_{2} & =325 \mathrm{~m} \mathrm{sec}^{-1}, & V_{1} & =215 \mathrm{~m} \mathrm{sec}^{-1}, \\
m_{t} c_{t} & =28 \mu \mathrm{J}\left({ }^{\circ} \mathrm{K}\right)^{-1}, & c_{x} & =1.0 \times 10^{7} \mathrm{~cm}^{2} \mathrm{sec}^{-2}\left({ }^{\circ} \mathrm{K}\right)^{-1} .
\end{aligned}
$$


The solution of Eq. (5.5) for $h_{t}$, with $A_{t}=3.210^{-3} \mathrm{~cm}^{2}$, gives a value for $h_{t}$ of $1.1 \times 10^{-4} \mathrm{cal} \mathrm{cm}^{-2} \mathrm{sec}^{-1}\left({ }^{\circ} \mathrm{K}\right)^{-1}$. The theoretical value of the convective heat transfer coefficient $h_{i}$ for the thermistor at $65 \mathrm{~km}$ is $4.0 \times 10^{-4}$ cal $\mathrm{cm}^{-2} \mathrm{sec}^{-1}\left({ }^{\circ} \mathrm{K}\right)^{-1}$.

b) Rates of change of thermistor temperature with time $(74 \mathrm{~km}-50 \mathrm{~km})$. It was shown in Fig. 5 that the net exchange of energy by long-wave radiation between the thermistor at $65 \mathrm{~km}$ and its environment was small relative to the convective and conductive modes of heat transfer. A similar calculation for the thermistor at $74 \mathrm{~km}$ indicates a net dissipation of energy to its environment by radiation of $20 \mu \mathrm{W}$.

Assume that the atmospheric temperature at $74 \mathrm{~km}$ is that of the U.S. 1962 Standard Atmosphere $\left(T_{e}=200 \mathrm{~K}\right)$ and that the temperature of the mylar film mount immediately after ejection from the rocket is at the thermistor temperature $\left(T_{f}=T\right)$. Fig. 12 indicates that the thermistor temperature immediately after instrument expulsion was approximately $300 \mathrm{~K}$ while the fall velocity $d z / d t$ was equal to zero. In Section $5 \mathrm{a}$, it was determined experimentally that the quantity $h_{t} A_{t}=1.43$ $\mu \mathrm{W}\left({ }^{\circ} \mathrm{K}\right)^{-1}$. By extrapolation, let the value of $h_{t} A_{t}$ at $74 \mathrm{~km}$ be $0.9 \mu \mathrm{W}\left({ }^{\circ} \mathrm{K}\right)^{-1}$. Then, the expression for the time rate of change of temperature of the thermistor at $74 \mathrm{~km}$ under the above conditions becomes

$$
\left.\begin{array}{c}
m_{\imath} c_{t} \frac{d T}{d t}=-20 \mu \mathrm{W}+h_{t} A_{t}\left(T_{e}-T\right) \\
m_{t} c_{t} \frac{d T}{d t}=-20 \mu \mathrm{W}-0.9(130) \mu \mathrm{W} \\
\frac{d T}{d t}=-\frac{137 \mu \mathrm{W}}{28 \mu \mathrm{J}\left({ }^{\circ} \mathrm{K}\right)^{-1}}=-5 \mathrm{~K} \mathrm{sec}{ }^{-1}
\end{array}\right\} .
$$

Thus, the theoretically predicted value for $d T / d t$ at $74 \mathrm{~km}$ is $-5 \mathrm{~K} \mathrm{sec}^{-1}$. From Fig. 11 and item 4), Section 4 , the observed value of $d T / d t$ was $-2.2 \mathrm{~K} \mathrm{sec}{ }^{-1}$. As the instrument descended $d T / d t$ changed from a negative value to a positive value of $+0.32 \mathrm{~K} \mathrm{sec}-1$ when the vertical velocity exceeded $215 \mathrm{~m} \mathrm{sec}^{-1}$. At an altitude of $69 \mathrm{~km}$ (Figs. 11, 12) the parachute opened, the vertical velocity changed from 325 to $225 \mathrm{~m} \mathrm{sec}^{-1}$. At this point $d T / d t$ was equal to $-1.05 \mathrm{~K} \mathrm{sec}-1$.

To determine the cause of the discrepancy between the calculated and the observed values of $d T / d t$ immediately after instrument expulsion, the horizontal component of the instrument velocity was determined at several altitude points below $74 \mathrm{~km}$. Given in Table 2 are the horizontal and vertical components of instrument velocity and the resultant velocity relative to the earth's surface.

The time rate of change thermistor temperature immediately after instrument expulsion was determined with consideration being given to the aerodynamic heating associated with the horizontal velocity component. From Eq. (5.6) and with a determined hori-
TABLE 2. Instrument velocities $(\mathrm{m} \mathrm{sec}-1)$.

\begin{tabular}{lccc}
\hline \hline $\begin{array}{c}\text { Altitude } \\
(\mathrm{km})\end{array}$ & Horizontal & Vertical & Resultant \\
\hline 74 & 300 & 0 & 300 \\
71 (Positive $d T / d t)$ & 300 & 215 & 370 \\
69 (Parachute open) & 300 & 325 & 450 \\
65 & 160 & 170 & 235 \\
64 & Parachute & 165 & $165+$ wind velocity \\
60 & wind & 125 & $125+$ wind velocity \\
50 & sensitive & 70 & $70+$ +wind velocity \\
\hline
\end{tabular}

zontal speed of $300 \mathrm{~m} \mathrm{sec}^{-1}$, recovery factor $r=1.25$, $h_{t} A_{t}=0.9 \mu \mathrm{W}\left({ }^{\circ} \mathrm{K}\right)^{-1}$ and $\left(T_{e}-T\right)=-130 \mathrm{~K}$, we have

$$
\begin{aligned}
& m_{t} c_{t} \frac{d T}{d t}=-20 \mu \mathrm{W} \text { (radiation) } \\
& \left.\begin{array}{c}
\quad+h_{t} A_{t}\left[T_{e}+\frac{r v^{2}}{2 c_{p}}-T\right] \\
m_{i} c_{t} \frac{d T}{d t}=-20 \mu \mathrm{W}+0.9[-130+56] \mu \mathrm{W} \\
\frac{d T}{d t}=-\frac{87}{28 \mu \mathrm{J}\left({ }^{\circ} \mathrm{K}\right)^{-1}}=-3 \mathrm{~K} \mathrm{sec}^{-1}
\end{array}\right\} .
\end{aligned}
$$

Comparison of the numerical values for $d T / d t$ from Eqs. (5.6) and (5.7) with the observed rates of change of temperature of the thermistor with time at an apogee altitude of $74 \mathrm{~km}$ shows that inclusion of aerodynamic heating associated with the horizontal component of velocity of $300 \mathrm{~m} \mathrm{sec}^{-1}$, gives a calculated value for $d T / d t$ of $-3 \mathrm{~K} \mathrm{sec}^{-1}$; the observed value is $-2.2 \mathrm{~K} \mathrm{sec}-1$.

It would appear that any corrections to observed thermistor temperature must include the horizontal velocity component in the aerodynamic heating calculation down to the altitude at which the parachute becomes fully wind sensitive.

c) Experimental determination of thermistor temperature corrections. Reference to Fig. 12 shows that the rate of change of the thermistor temperature with altitude becomes zero at $64 \mathrm{~km}$. The long-wave radiation correction to the thermistor temperature was shown to be negligible at $65 \mathrm{~km}$ (Fig. 5). Thus, for the temperature-height data at $65 \mathrm{~km}$, the thermistor heat transfer equation becomes

$$
m_{t} c_{t} \frac{d T}{d z} \frac{d z}{d t}=\frac{2 K \beta}{X_{m}}\left[T_{f}-T\right]+h_{t} A_{t}\left[T_{e}+\frac{r V^{2}}{2 c_{p}}-T\right]=0 .
$$

Substituting the values $2 K \beta / X_{m}=10 \mu \mathrm{W}\left({ }^{\circ} \mathrm{K}\right)^{-1}, h_{t} A_{t}$ $=5 \mu \mathrm{W}\left({ }^{\circ} \mathrm{K}\right)^{-1}$ and $r V^{2} / 2 c_{p}=15 \mathrm{~K}$ (at $65 \mathrm{~km}$ ) into $\mathrm{Eq}$. (5.8) gives

$$
10\left(T_{f}-T\right)+5\left(T_{e}-T\right)+75=0 .
$$

If the temperature of the film $T_{f}=T$, then from Eq. (5.9), $T_{e}-T=-15 \mathrm{C}$. If the temperature of the film $T_{f}=T_{e}$, then $T_{e}-T=-5 \mathrm{C}$. Thus, the thermistor tem- 


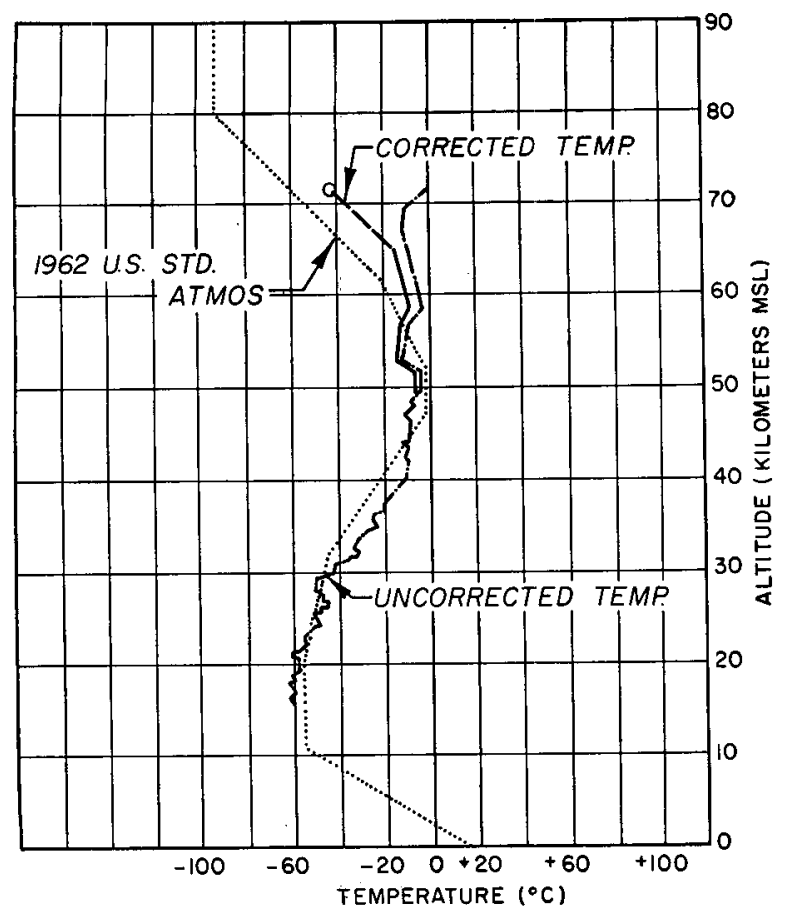

STATION_WSMR, N.M.

ROCKET TYPE ARCAS STS - I (5)

DATE 15 MARCH 1966 TIME 2004 Z (BOH MST)

FIG. 13. Temperature-altitude profiles, STS-1 instrument, showing uncorrected and corrected temperatures (Table 3).

perature at $65 \mathrm{~km}$ lies between the limits

$$
T_{e}+5 \mathrm{~K} \leq T_{65} \leq T_{e}+15 \mathrm{~K} \text {. }
$$

The aerodynamic temperature increase at $60 \mathrm{~km}$ is $6 \mathrm{~K}$ while the term $h_{t} A_{t}$ has a value of $7 \mu \mathrm{W}\left({ }^{\circ} \mathrm{K}\right)^{-1}$. From Fig. 12, a calculation identical to that of Eq. (5.8) and (5.9) gives

$$
T_{e}+2.5 \mathrm{~K}=T_{60} \leq T_{e}+6.0 \mathrm{~K} .
$$

The same calculation for $50 \mathrm{~km}$ with $h_{t} A_{t}=20 \mu \mathrm{W}\left({ }^{\circ} \mathrm{K}\right)^{-1}$ and $r V^{2} / 2 c_{p}=1.5 \mathrm{~K}$ gives

$$
T_{e}+1.0 \mathrm{~K} \leq T_{50} \leq T_{e}+1.5 \mathrm{~K} .
$$

\section{Summary}

The improved response of the stratospheric temperature sonde (STS-1) is indicated in Figs. 11 and 12. The sensitivity of the temperature sensing instrument made possible the detection of a change in thermistor temperature of $+3 \mathrm{C}$ when the fall velocity changed from 215 to $325 \mathrm{~m} \mathrm{sec}^{-1}$ just prior to the time of parachute opening. Calculations based upon these data (Section 5a) led to a determination of the thermistor convective heat transfer coefficient at $70 \mathrm{~km}$ which agreed favorably with its theoretically determined value.

A study of the slope of the temperature-time record of Fig. 11 shows that the value of $d T / d t$ at the time of sensor expulsion from the rocket was increased to a value of $-2.2 \mathrm{~K} \mathrm{sec}-1$ for the STS-1 instrument. The inclusion of the horizontal component of instrument velocity in the correction for aerodynamic heating gave a theoretical value for $d T / d t$ at time of expulsion of $-3 \mathrm{~K} \sec ^{-1}$.

The improved response and sensitivity of the instrument was accomplished through the utilization of a heat dissipative mylar mount between the sensing thermistor and instrument body, reduction in the electrical power across the thermistor, and the matching of the instrument and thermistor characteristics (Section 3b).

The development of a mathematical expression for the dissipation factor $S$ (Section 2) gave a means of predicting the temperature rise for a given rate of heat energy input to the thermistor and mylar film mount. The calculated values for the thermistor and film dissipation factors at $65 \mathrm{~km}$ were 16 and $5200 \mu \mathrm{W}\left({ }^{\circ} \mathrm{K}\right)^{-1}$, respectively, with corresponding time constants of 1.8 and $0.7 \mathrm{sec}$. The transmittance-wavelength study in the spectral region from 0.2 to $2.4 \mu$ for the mylar film indicated that the temperature increase in the thermistor due to the absorption of solar radiation when mounted on the aluminum-coated mylar film is approximately 1C (approximately 4C for uncoated mylar).

The magnitudes of the temperature differences between the mylar film mounted thermistor and the atmosphere at altitudes of 65,60 , and $50 \mathrm{~km}$ were empirically determined from Fig. 12 when the rate of change of temperature with altitude was zero. These were:

$$
\begin{array}{ll}
T_{e}+5 \mathrm{~K} \leq T \leq T_{e}+15 \mathrm{~K} & 65 \mathrm{~km} \\
T_{e}+2.5 \mathrm{~K} \leq T \leq T_{e}+6 \mathrm{~K} & 60 \mathrm{~km} \\
T_{e}+1.0 \mathrm{~K} \leq T \leq T_{e}+1.5 \mathrm{~K} & 50 \mathrm{~km}
\end{array}
$$

Table 3 gives the theoretically computed correction to the observed thermistor temperature for the STS-1 instrument at the indicated fall velocities and altitudes. The corresponding correction for the Delta-I instrument is given for the purpose of comparison.

Fig. 13 shows the temperature-altitude profile obtained with stratospheric temperature sonde STS-1 and the profile as corrected according to the values given in Table 3.

An insulating shield was placed around the instrument thermistor and thin film mount in the rocket nose cone such that the maximum temperature in the nose

TABLE 3. Temperature correction factors for the STS-1 and Delta-I instruments.

\begin{tabular}{cccc}
\hline $\begin{array}{c}\text { Altitude } \\
(\mathrm{km})\end{array}$ & $\begin{array}{c}\text { Fall } \\
\text { velocity } \\
\left(\mathrm{m} \mathrm{sec}^{-1}\right)\end{array}$ & $\begin{array}{c}\text { STS-1 } \\
\text { correction } \\
\left({ }^{\circ} \mathrm{K}\right)\end{array}$ & $\begin{array}{c}\text { Delta-I } \\
\text { correction } \\
\left({ }^{\circ} \mathrm{K}\right)\end{array}$ \\
\hline 65 & 167 & -6.2 & -35.5 \\
00 & 125 & -3.8 & -20.5 \\
55 & 90 & -2.2 & -8.5 \\
50 & 61 & -1.1 & -5.4
\end{tabular}


cone prior to the time of instrument expulsion was $45 \mathrm{C}$. In addition, a parachute identified as a "disk-gap-band" mylar parachute ${ }^{2}$ replaced the conventional "hemispherical" silk parachute discussed in Section 2 and was utilized to support the stratospheric temperature sonde from which the temperature-altitude profile of Fig. 13 was obtained.

The differences in the temperature-altitude profiles of Figs. 12 and 13 in the vicinity of $70 \mathrm{~km}$ can be attributed primarily to the differences in the deployment characteristics of the two types of parachutes.

In Fig. 13 the temperature indicated by the circle at an altitude of $74 \mathrm{~km}$ is the temperature obtained when the observed thermistor temperature was corrected for the aerodynamic heating of the thermistor associated with the horizontal component of instrument velocity of $313 \mathrm{~m} \mathrm{sec}^{-1}$ when the vertical component of velocity was zero. The dashed line joins this temperature-altitude point to the temperature value at $65 \mathrm{~km}$ as corrected according to the theoretical correction values given in Table 3 , thus giving a semi-empirical temperature-altitude profile in the interval from 74 to $65 \mathrm{~km}$.

${ }^{2}$ Murrow, H. N., and C. V. Eckstrom, 1966: Description of a new parachute for use with meteorological rockets and a consideration of improvements in meteorological measurements. Preprint No. 66-399, Sixth Conf. Applied Meteorology (Aerospace Meteorology), Amer. Meteor. Soc., Los Angeles, Calif.
Acknoreledgments. I wish to thank the personnel of the Atmospheric Sciences Laboratory (ASL), White Sands Missile Range and the personnel of Schellenger Research Laboratories (SRL), The University of Texas at El Paso, who contributed to the research and development program described in this report. I wish to particularly thank Mr. Claude Tate (ASL) and Mr. Mike Izquierdo (SRL) for instrument development, Mr. Bun Ling Yee (SRL) for sensor calibrations and thermistor mount construction, Mr. Cantrell Craig (SRL) for data reduction, Prof. John Whitacre (SRL), and Mr. Bruce Kennedy (ASL) for engineering services.

\section{REFERENCES}

Barr, W. C., 1961: Theoretical considerations in the design of atmospheric temperature-sensing elements. USASRDL Tech. Report 2195, Ft. Monmouth, N. J., 15 pp.

Beyers, N. J., O. W. Thiele and N. K. Wagner, 1962 : Performance characteristics of meteorological rocket wind and temperature sensors. Technical Report SELWS-M-4, U. S. Army Electronics Research and Development Activity, White Sands Missile Range, N. Mex., $30 \mathrm{pp}$.

Clark, G., and J. McCoy, 1965: Measurement of stratospheric temperature. J. Appl. Meteor., 3, 365-370.

Ramsdale, D. J., 1965: Theoretical time constant for the thin film temperature sensor. Tech. Report, Schellenger Research Laboratories, Texas Western College, El Paso, Tex., 15 pp.

Wagner, N. K., 1964: Theoretical accuracy of a meteorological rocketsonde thermistor. $J$. Appl. Meleor., 3, 461-469. 